\title{
Critical roles for IL-4, IL-5, and eosinophils in chronic skin allograft rejection
}

\author{
Alain Le Moine, ${ }^{1,2}$ Véronique Flamand, ${ }^{1}$ François-Xavier Demoor, ${ }^{1}$ \\ Jean-Christophe Noël, ${ }^{3}$ Murielle Surquin, ${ }^{1,2}$ Robert Kiss, ${ }^{4}$ Marie-Anne Nahori, ${ }^{5}$ \\ Marina Pretolani, ${ }^{6}$ Michel Goldman, ${ }^{1}$ and Daniel Abramowicz ${ }^{2}$ \\ ${ }^{1}$ Laboratory of Experimental Immunology, Faculty of Médecine, \\ ${ }^{2}$ Department of Nephrology, Hopital Erasme, \\ ${ }^{3}$ Department of Pathology, Hopital Erasme, and \\ ${ }^{4}$ Laboratory of Histology, Faculty of Médecine, Université Libre de Bruxelles, B-1070 Brussels, Belgium \\ ${ }^{5}$ Unit of Cellular Pharmacology, Associated Unit of Pasteur Institute/Institut National de la Santé et de la Recherche Médicale \\ (INSERM) Unit 485, 75018 Paris, France \\ ${ }^{6}$ INSERM Unit 408, Faculté de Médecine Xavier-Bichat, 75724 Paris, France
}

Address correspondence to: Daniel Abramowicz, Department of Nephrology, Hopital Erasme, 808 Route de Lennik, B-1070 Brussels, Belgium. Phone: 32-2-555-33-34; Fax: 32-2-555-64-99; E-mail: alemoine@ulb.ac.be.

Received for publication October 14, 1998, and accepted in revised form May 11, 1999.

\begin{abstract}
C57BL/ 6 mice injected with the 145-2C11 anti-CD3 mAb and grafted with MHC class II disparate bm12 skin develop a chronic rejection characterized by interstitial dermal fibrosis, a marked eosinophil infiltrate, and an obliterative intimal vasculopathy. Because these changes occur in the absence of alloreactive antibodies, we examined the contribution of cytokines in their pathogenesis. Chronically rejected grafts showed a marked accumulation of both IL-4 and IL-5 mRNA. Mixed lymphocyte reaction experiments established that mice undergoing chronic rejection were primed for IL-4, IL-5, and IL-10 secretion. In vivo administration of anti-IL-4 mAb completely prevented allograft vasculopathy as well as graft eosinophil infiltration and dermal fibrosis. Injection of anti-IL-5 $\mathrm{mAb}$ or the use of IL-5-deficient mice as recipients also resulted in the lack of eosinophil infiltration or dermal fibrosis, but these mice did develop allograft vasculopathy. Administration of anti-IL-10 mAb did not influence any histologic parameter of chronic rejection. Thus, in this model, IL-4- and IL-5-mediated tissue allograft eosinophil infiltration is associated with interstitial fibrosis. IL-4, but not eosinophils, is also required for the development of obliterative graft arteriolopathy.
\end{abstract}

J. Clin. Invest. 103:1659-1667 (1999).

\section{Introduction}

Chronic rejection of tissue allografts is characterized by parenchymal fibrosis associated with obliterating vasculopathy (1). The pathogenesis of this major complication of solid-organ transplantation is still unclear, and probably involves both antibody-mediated and cellmediated processes (2-6). We recently described a model of chronic skin allograft rejection across a single MHC class II antigen disparity in mice injected with the 145$2 \mathrm{C} 11$ anti-CD3 $\mathrm{mAb}$ at the time of transplantation (7). In this setting, fibrosis and vasculopathy are not mediated by antibodies, as demonstrated by the development of chronic rejection in B cell-deficient mice (7). Furthermore, recipient $\mathrm{T}$ cells were unable to mount anti-donor cytotoxic activity (7). The observation of an intense infiltration of eosinophils early after transplantation in both $B$ cell-deficient and wild-type mice suggests that these cells might be involved in the chronic remodeling of skin allografts. Indeed, eosinophils are known to play a crucial pathogenic role in several models of tissue fibrosis (8-15). In most eosinophilic disorders, IL-5 produced by Th2-type CD4 T cells was found to be responsible for the proliferation, activation, and tissue recruitment of eosinophils (16-18). In addition, IL-4 also plays a pathogenic role in tissue eosinophilia: it promotes IL-5 pro- duction as well as the homing of eosinophils within tissues $(19,20)$. Because anti-CD3 antibodies have been shown to preferentially inhibit Th1-type responses and to promote the synthesis of Th2-type cytokines $(21,22)$, we reasoned that IL-4 and IL-5 produced by persisting anti-donor alloreactive $\mathrm{T}$ cells might play a pathogenic role in this model of chronic rejection.

To address this question, we first analyzed cytokine gene expression at the graft level using RT-PCR. The local accumulation of IL-4 and IL-5 mRNA in chronically rejected grafts, together with the early and sustained production of IL- 5 by anti-donor T cells in mixed leukocyte culture (MLC), prompted us to analyze the effects of in vivo neutralization of both cytokines on the development of chronic rejection.

\section{Methods}

Mice. C57BL/6 and BALB/c mice were obtained from Harlan (Zeist, the Netherlands). C57BL/6.CH-2 $2^{\text {bm12 }}$ (bm12) mice were obtained from The Jackson Laboratory (Bar Harbor, Maine, USA). C57BL/6 IL-5 knockout mice (23) were kindly provided by M. Kopf (Basel Institute for Immunology, Basel, Switzerland).

Antibodies. The hamster anti-mouse CD3 mAb 145-2C11, the IgG1 rat anti-mouse IL-5 mAb TRFK-5, the IgG1 rat antimouse IL-4 mAb 11B11, and the IgG1 rat anti-mouse IL-10 


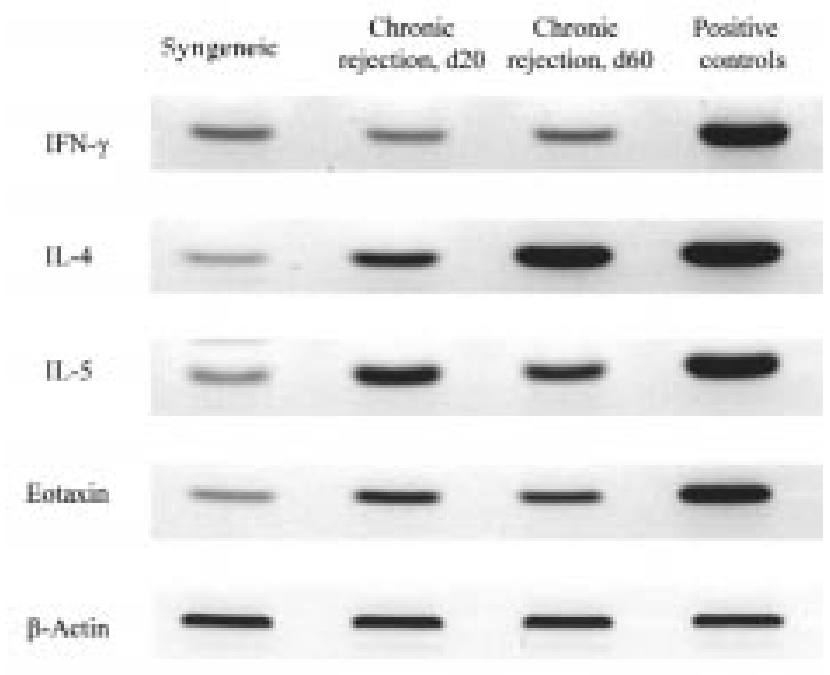

Figure 1

Cytokine gene expression within chronically rejected allografts. Cytokine gene expression was assayed within pooled syngeneic C57BL/ 6 grafts $(n=4)$ or bm 12 allografts undergoing chronic rejection at either day $20(n=4)$ or day $60(n=4)$ after transplantation. Lymph node cells from C57BL/ 6 mice stimulated in vivo with the $2 \mathrm{C} 11$ antiCD3 mAb served as positive controls. Similar results were observed in 2 other separate experiments.

mAb JES-5 were all produced as ascites in nude mice, as described (24-27). The control isotype-matched IgG1 rat mAb (LO-DNP-2, an mAb with specificity for the DNP hapten) was kindly provided by $\mathrm{H}$. Bazin (Experimental Immunology Unit, Université Catholique de Louvain, Brussels, Belgium). The endotoxin level of ascites was always less than $5 \mathrm{EU} / \mathrm{mL}$, as determined by the Coatest Limulus Amebocyte Lysate assay (Charles River Endosafe, Charleston, South Carolina, USA).

Skin grafting. Skin grafts approximately $1 \mathrm{~cm}$ in diameter were prepared from tails of female bm 12 mice and grafted onto the flanks of the C57BL $/ 6$ recipients according to an adaptation of the method of Billingham and Medawar (28). Petroleum gauze was placed over the graft, and sticking plaster was applied around the trunk. The bandages were removed after 10 days, and the grafts were monitored daily until day 30 , and then again every 2 days.

Immunosuppressive protocol and chronic skin allograft rejection. Mice received a first intravenous injection of $25 \mu \mathrm{g}$ of the hamster anti-murine CD3 mAb $145-2 \mathrm{C} 11$ on the day of grafting, followed by 3 consecutive intraperitoneal injections of $25 \mu \mathrm{g}$ anti-CD3 $\mathrm{mAb}$ on days 2,4 , and 6 . As described previously, about $80 \%$ of animals receiving this treatment retain a bm 12 skin graft for more than 100 days but develop signs of chronic rejection characterized by progressive hair loss and hardening and shrinking of the graft (7). Mice that were not treated with

\section{Table 1}

Competitive quantitative RT-PCR assay of cytokine mRNA within chronically rejected skin grafts

\begin{tabular}{lcc}
\hline Cytokine $^{A}$ & Syngeneic grafts $^{B}$ & Allogeneic grafts $^{B}$ \\
IFN- $\gamma$ & 47 & 55 \\
IL-4 & 9 & 291 \\
IL-5 & 3 & 10
\end{tabular}

AExpressed as femtograms of cytokine mRNA per microgram of cellular RNA. Each experimental group represents a pool of 3 skin grafts. BSyngeneic C57BL/6 and allogeneic (bm12) grafts were harvested 40 days after transplantation.
anti-CD3 mAb acutely rejected bm 12 grafts within 20 days, whereas syngeneic grafts were perfectly tolerated (7).

Cytokine $m R N A$ analysis using RT-PCR. Skin grafts from mice bearing either a syngeneic C57BL/ 6 transplant or allogeneic bm12 grafts undergoing chronic rejection 20 days and 60 days after transplantation were analyzed for cytokine and chemokine mRNA. In each experimental setting, 4 skin grafts were pooled and total RNA was extracted using the guanidinium thiocyanate method (Tripure; Boehringer Mannheim $\mathrm{GmbH}$, Mannheim, Germany). Lymph node cells from C57BL/6 mice injected previously with the anti-CD3 145-2C11 $\mathrm{mAb} 2$ hours before sacrifice served as positive controls for cytokine gene expression. Preparations of $\mathrm{CDNA}$ and PCR for IFN- $\gamma$, IL-4, IL-5, eotaxin, TGF- $\beta$, and the $\beta$-actin gene were performed using standard procedures (29). Briefly, PCR was performed in a total volume of $25 \mu \mathrm{L}$ as follows: (a) denaturation: 4 minutes at $94^{\circ} \mathrm{C}$; (b) amplification: 38 cycles for IL-5 and 35 cycles for the other cytokines, 20 seconds at $94^{\circ} \mathrm{C}, 20$ seconds at $55^{\circ} \mathrm{C}$, and 30 seconds at $72^{\circ} \mathrm{C}$; and (c) extension: 10 minutes at $72^{\circ} \mathrm{C}$. Twelve microliters of each sample was run on a $2 \%$ agarose gel, stained with ethidium bromide, and viewed using ultraviolet light. PCR primers used consisted of the following: IFN- $\gamma$ : sense primer $5^{\prime}$-GCTCTGAGACAATGAACGCT-3' and antisense 5'-AAAGAGATAATCTGGCTCTGC-3'; IL-4: sense primer 5'-TCGGCATTTTGAACGAGGTC-3' and antisense $5^{\prime}$-GAAAAGCCCGAAAGAGTCTC-3'; IL-5: sense primer $5^{\prime}$-TCACCGAGCTCTGTTGACAA-3' and antisense 5'-CCACACTTCTCTTTTTGGCG-3'; eotaxin: sense primer 5'-AGAGGCTGAGATCCAAGCAG-3' and antisense 5'-CAGATCTCTTTGCCCAACCT-3'; TGF- $\beta$ : sense primer $5^{\prime}$-ACCGCAACAACGCCATCTAT- $3^{\prime}$ and antisense $5^{\prime}$ GTAACGCCAGGAATTGTTGC- $3^{\prime}$; and $\beta$-actin: sense primer $5^{\prime}$-TGGAATCCTGTGGCATCCATGAAAC- $3^{\prime}$ and antisense 5'-AAAACGCAGCTCAGTAACAGTCCG-3'.

Quantitative RT-PCR assay. The amounts of TGF- $\beta$, IFN- $\gamma$, IL4, and IL-5 mRNA present in skin allografts were determined by quantitative PCR analysis. Coamplification with a multispecific internal standard (competitor) was performed as described previously (29), using the pMus 2 construction kindly provided by D. Shire (Sanofi Elf Bio Recherches, LabègesInnopole, France). This construction is a multispecific standard of $410 \mathrm{bp}$ that consists of the $5^{\prime}$ and $3^{\prime}$ primer sequences of 19 mouse target genes. After linearization with EcoRI followed by transcription using a T7 polymerase and a DNA treatment, standard RNA was purified by phenol/chloroform extraction and ethanol precipitation, and quantified at $260 \mathrm{~nm}$. Seventyfive femtograms of this standard RNA was added as competitor to $500 \mathrm{ng}$ of cellular RNA before reverse transcription and coamplification with the TGF- $\beta$ primers. Twelve microliters of each sample was run on $2 \%$ agarose gel and quantified with Multi-Analyst PC software (Bio-Rad Laboratories Inc., Hercules, California, USA).

Production of cytokines in MLC. Cells from lymph nodes draining the skin allografts were used as responder cells $\left(2.5 \times 10^{6}\right.$ cells per well) and seeded with $5 \times 10^{6}$ irradiated ( 20 Gy) bm 12 spleen cells (stimulators) in 48-well flat-bottomed plates (catalog no. 150687; Nunc A/S, Roskilde, Denmark). Culture medium consisted of RPMI-1640 supplemented with 20 mM HEPES, 2 mM glutamine, $1 \mathrm{mM}$ nonessential amino acids, $2.5 \%$ heat-inactivated FCS, and $5 \times 10^{-5} \mathrm{M} 2$-mercaptoethanol. Supernatants were harvested after 48-72 hours of culture for determination of IL-2, IL-4, and IFN$\gamma$ levels using ELISA DuoSet kits (Genzyme Corp., Cambridge, Massachusetts, USA); IL-10 was measured using the Intertest-10x mouse IL-10 ELISA kit (Genzyme Corp.); and IL-5 was quantified by an enzyme immunometric assay as described previously (30). The lower limits of detection of these assays were $30 \mathrm{pg} / \mathrm{mL}$ for IL2, IL-4, and IFN- $\gamma ; 15 \mathrm{pg} / \mathrm{mL}$ for IL-10; and $5 \mathrm{pg} / \mathrm{mL}$ for IL-5.

In vivo neutralization of cytokines. Anti-CD3-treated mice were 
injected intraperitoneally with either the anti-cytokine $\mathrm{mAb}$ or the control isotype-matched IgG1 rat mAb (LO-DNP-2) using the following schedules: anti-IL-4 mAb (11B11): $1 \mathrm{mg}$ on days 6,10 , and 14 after transplantation, and then again every 7 days (31); anti-IL-10 mAb (JES-5): $1 \mathrm{mg}$ on days 6, 8, and 10 after transplantation, and then again every 3 days (27); and anti-IL$5 \mathrm{mAb}$ (TRFK-5): $1 \mathrm{mg}$ on days 6 and 10 after transplantation, and then again every 10 days.

Histologic studies. Skin graft histology was performed on tissue sections after paraffin embedding and staining with hematoxylin and eosin, Masson's dye, and orcein to identify the lamina elastica interna. Graft lesions were scored by an investigator blinded to treatment groups. A single section of skin graft was considered for each experimental animal. The following histologic lesions were quantified: (a) the number of eosinophils present in 3 distinct high-power fields $\left(0.025 \mathrm{~mm}^{2}\right)$ across the graft $(1$ in the left portion of the section, 1 in the middle, and 1 in the right); (b) the ratio between the thickness of dense collagen within the dermis and the thickness of the whole dermis as an index of fibrosis (of note, the expression of this parameter as a ratio is likely to validate the analysis of the sections in case they are not perfectly perpendicular to the skin surface); and (c) the percentage of the intimal area, defined as the area occupied by the intima/(area occupied by the intima + area of the lumen) $\times 100$. These measurements were made using a computer-assisted technique: Samba 2005 computer-assisted microscope (Unilog, Meylan, France) coupled to a 3 CCD Sony color camera. The number of vascular lumens per section varied between 1 and 5 , with no obvious difference between the various experimental groups. A vessel was considered suitable for computer analysis if the lamina elastica interna was continuous and of circular or oval shape. For TGF- $\beta 1$ immunostaining, $5-\mu \mathrm{m}$ sections were incubated overnight at $4^{\circ} \mathrm{C}$ with a $1: 100$ dilution of the affinity-purified rabbit polyclonal antibody directed against mouse TGF- $\beta 1$ (sc-146; Santa Cruz Biotechnology Inc., Santa Cruz, California, USA). Bound antibodies were revealed by avidin-biotin-peroxidase complex $(\mathrm{ABC})$ kit reagents (Vector Laboratories, Burlingame, California, USA), with diaminobenzidine $/ \mathrm{H}_{2} \mathrm{O}_{2}$ as the chromogenic substrate, before counterstaining with toluidine blue. As control, the overnight incubation was performed in the presence of the blocking TGF- $\beta 1$ peptide (sc-146P) as described by the manufacturer.

Statistical analysis. Categorical variables were compared by Fisher's exact test, and continuous variables by nonparametric tests. The Mann-Whitney test was used when 2 experimental groups were compared, and the Kruskal-Wallis ANOVA test was used when more than 2 groups were considered. All comparisons were made two-tailed.

\section{Results}

Cytokine gene expression in chronically rejected skin grafts. The pattern of cytokine gene expression within syngeneic grafts was characterized by the absence of IL-4 mRNA, low levels of IFN- $\gamma$ and IL-5 mRNA, and a sustained expression of eotaxin mRNA. While chronically rejected allografts contained IFN- $\gamma$ mRNA levels similar to those of syngeneic grafts, they strongly expressed IL-5 mRNA both at day 20 and day 60 after transplantation (Figure 1). Similarly, increased expression of IL-4 mRNA was already apparent at day 20, and further increased at day 60 in chronically rejected allografts (Figure 1). A higher expression of eotaxin mRNA was also observed in chronically rejected skin allografts compared with syngeneic skin grafts (Figure 1). Quantitative RT-PCR confirmed that, compared with syngeneic grafts, chronically rejected skins contained increased amounts of IL-4 and IL-5 mRNA but not IFN- $\gamma$ mRNA (Table 1 ).

Profile of cytokines secreted by anti-donor T cells in MLC. Cells from lymph nodes draining chronically rejected allografts were seeded in MLC with either donor-type or syngeneic spleen cells, and cytokine levels in supernatants were compared with those obtained using lymph node cells from unmanipulated control C57BL/6 mice (Table 2). Cells from control mice produced significant amounts of IL-2, IFN- $\gamma$, and IL-5, but neither IL-4 nor IL-10 was detected in primary MLC with bm12 alloantigens. At day 20, anti-donor T cells from mice undergoing chronic rejection were deficient for the production of both IL-2 and IFN- $\gamma$, as expected after anti-CD3 mAb administration $(21,22)$. This contrasted with the abundant release of IL-5, which was approximately 2 -fold higher than that observed after primary MLC with control cells $(P=0.01)$. This phenomenon was specific for donor alloantigens, since IL5 was not induced in MLC prepared with third-party BALB/c spleen cells as stimulators (data not shown). At day 60 after transplantation, anti-donor $T$ cells from anti-CD3 mAb-treated mice still produced increased levels of IL-5. In addition, at that time they also produced increased levels of IFN- $\gamma$, IL- 4 , and IL-10 compared with control cultures (Table 2).

Effect of IL-4 neutralization on chronic allograft lesions. The abundant IL-4 mRNA expression at the graft level, together with its known role in the development of tissue eosinophilia (32-37), an important feature of chronically rejected bm 12 skins, led us to investigate the effects of IL-4 neutralization on chronic rejection. For this purpose, mice were treated repeatedly with either the neutralizing anti-IL-4 mAb (11B11) or the control-isotype matched IgG1 rat mAb (LO-DNP2). Mice that received the control $\mathrm{mAb}$ after anti-CD3

Table 2

Pattern of cytokine production in mixed lymphocyte reactions

\begin{tabular}{lcccccc}
\hline $\begin{array}{l}\text { Responder } \\
\text { mice }\end{array}$ & $\begin{array}{c}\text { Stimulator } \\
\text { cells }\end{array}$ & IL-2 & IFN- $\gamma$ & IL-4 & IL-5 & IL-10 \\
Controls & $\mathrm{bm} 12$ & $211(70-566)$ & $204(88-874)$ & $14(30-62)$ & $733(248-3,049)$ & $63(36-257)$ \\
& $\mathrm{C} 57 \mathrm{BL} / 6$ & $<30$ & $52(30-151)$ & $<30$ & $110(49-209)$ & $46(15-66)$ \\
Chronic rejection & $\mathrm{bm} 12$ & $69(34-196)^{\mathrm{B}}$ & $106(14-419)^{\mathrm{C}}$ & $7(30-59)$ & $1,614(1,093-3,711)^{\mathrm{D}}$ & $76(45-1,517)$ \\
day 20 & $\mathrm{C} 57 \mathrm{BL} / 6$ & $<30$ & $41(30-206)$ & $<30$ & $161(100-484)$ & $48(39-54)$ \\
$\begin{array}{l}\text { Chronic rejection } \\
\text { day } 60\end{array}$ & $\mathrm{bm} 12$ & $147(30-249)$ & $471(151-4,179)^{\mathrm{C}}$ & $75(30-430)^{\mathrm{B}}$ & $1,815(429-3,826)^{\mathrm{D}}$ & $614(59-3,842)^{\mathrm{B}}$ \\
& $\mathrm{C} 57 \mathrm{BL} / 6$ & $<30$ & $35(30-54)$ & $<30$ & $51(32-71)$ & $47(15-96)$
\end{tabular}

$\mathrm{IL}-2, \mathrm{IFN}-\gamma, \mathrm{IL}-4, \mathrm{IL}-5$, and IL-10 levels $(\mathrm{pg} / \mathrm{mL})$ in mixed lymphocyte reactions against donor-type allogeneic bm 12 or syngeneic C57BL/ 6 stimulator spleen cells are shown. For each experimental condition, 10-17 mice were tested. Results are expressed as median, with minimum and maximum values in brackets. ${ }^{\mathrm{A} U n m a n i p u l a t e d} \mathrm{C} 57 \mathrm{BL} / 6$ mice. ${ }^{\mathrm{B}} P<0.001,{ }^{\mathrm{C}} P<0.05,{ }^{\mathrm{D}} P<0.01$ compared with control mice. 

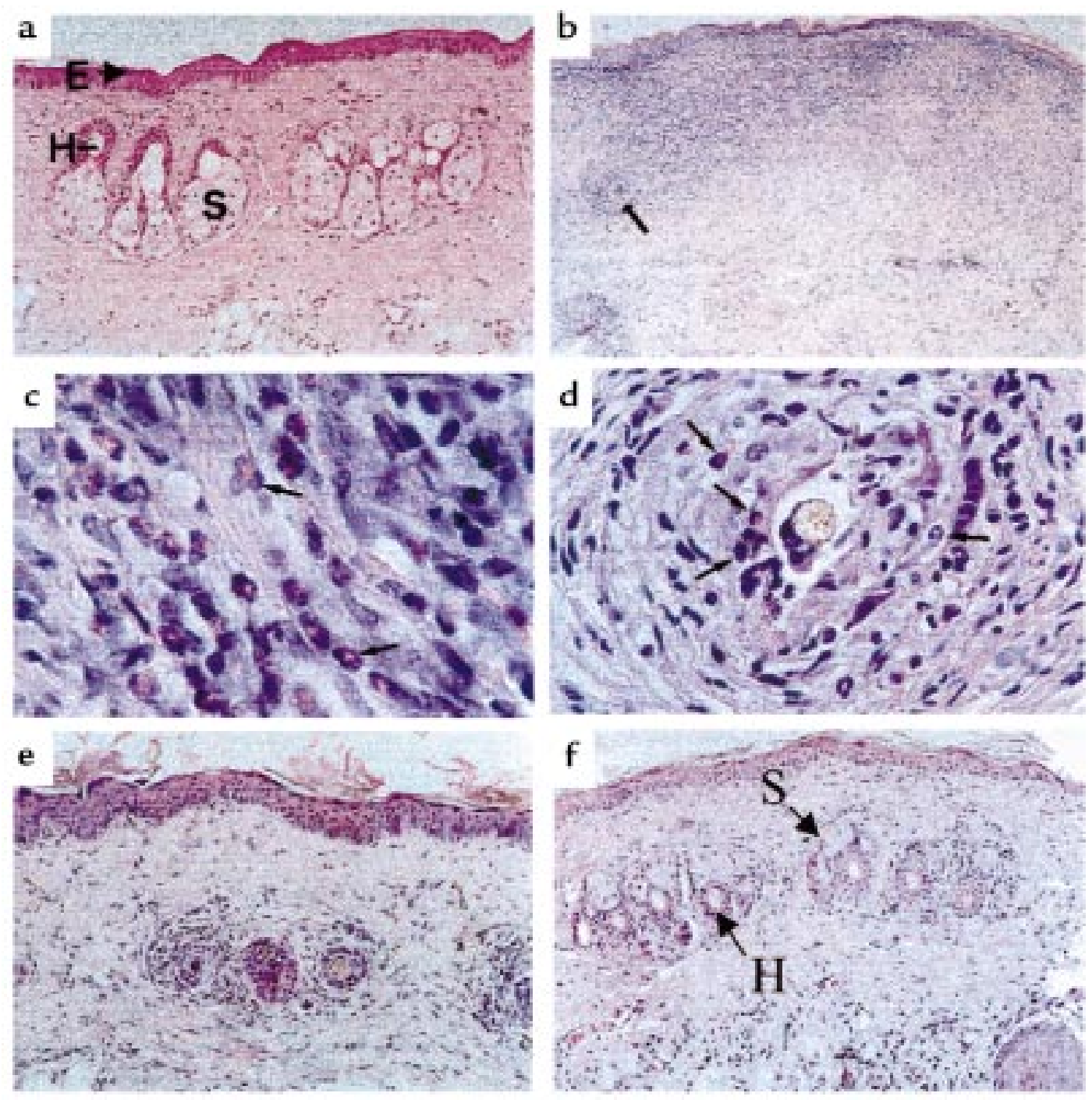

Figure 2

Allograft eosinophil infiltrate: effect of anti-IL-4 and anti-IL-5 mAb administration. (a) Syngeneic skin graft 40 days after transplantation. The dermis, below the epidermal layer (E), is free of inflammatory cells. Sebaceous glands (S) and hair follicles (H) show a normal appearance (hematoxylin and eosin, $\times 200$ ). (b) bm12 skin allografts at day 40 from a mouse that received anti-CD3 and the control mAb. There is a massive infiltration of the dermis by leukocytes. Up to $35 \%$ of the infiltrating leukocytes were identified as eosinophils (refer to c). The number of sebaceous glands and hair follicles is reduced, and those remaining are being engulfed by inflammatory cells (arrow) (hematoxylin and eosin, $\times 100$ ). (c) bm12 skin allografts at day 40 from a mouse that received anti-CD3 and the control mAb. The dermis is heavily infiltrated by eosinophils, recognizable by the red spots in the cytoplasm (arrows) (hematoxylin and eosin, $\times 1,000$ ). (d) bm 12 skin allografts at day 40 from a mouse that received anti-CD3 and the control mAb. A shrinking hair follicle is being infiltrated by numerous eosinophils (arrows) (hematoxylin and eosin, $\times 400)$. (e) bm12 skin allografts at day 40 from a mouse that received anti-CD3 and anti-IL-4 mAb. The aspect is similar to that of a syngeneic graft. The dermis is free of eosinophils. (f) bm12 skin allografts at day 40 from a mouse that received anti-CD3 and anti-IL$5 \mathrm{mAb}$. There is only a small number of leukocytes present in the dermis. The structure of hair follicles $(\mathrm{H})$ and sebaceous glands $(\mathrm{S})$ are well preserved (compare with $\mathbf{b}$ ) (hematoxylin and eosin, $\times 200$ ).

therapy developed chronic rejection of bm 12 skin allografts that was indistinguishable from the rejection occurring after the administration of the anti-CD3 $\mathrm{mAb}$ alone (7). There was a dense eosinophil infiltrate already apparent at day 20 that persisted until day 40 after transplantation (Figure 2, b and d; Table 3). As with the anti-CD3 $\mathrm{mAb}$-treated mice, these skin allografts displayed a 2 -fold increase in the amount of dense collagen deposits within the dermis, as well as a progressive, significant thickening of the arterial inti- ma (Figure 3b, Figure 4b, and Table 3). Macroscopically, about $50 \%$ of these mice developed graft hardening and showed a loss of hair at day 40 (Table 3). Repetitive administration of the anti-IL-4 mAb (11B11) resulted in the complete prevention of chronic rejection. Indeed, bm12 allografts did not display any interstitial fibrosis (Figure $3 \mathrm{c}$ and Table 3 ) or vasculopathy (Figure $4 \mathrm{c}$ and Table 3), and the eosinophil infiltrate present in control animals was absent (Figure $2 \mathrm{e}$ and Table 3). Macroscopically, the grafts were intact. 
Table 3

Effects of IL-4, IL-5, and IL-10 neutralization on chronic skin allograft rejection

\begin{tabular}{|c|c|c|c|c|c|c|}
\hline & \multirow[b]{2}{*}{$\begin{array}{l}\text { Syngeneic grafts }{ }^{A} \\
\quad(n=14)\end{array}$} & \multicolumn{5}{|c|}{ Allogeneic grafts ${ }^{A}$} \\
\hline & & $\begin{array}{l}\text { Control mAb } \\
\quad(n=13)\end{array}$ & $\begin{array}{l}\text { Anti-IL-4 mAb } \\
\quad(n=8)\end{array}$ & $\begin{array}{l}\text { Anti-IL-5 mAb } \\
\quad(n=18)\end{array}$ & $\begin{array}{l}\text { IL-5-deficient } \\
\text { mice }(n=10)\end{array}$ & $\begin{array}{l}\text { Anti-IL-10 mAb } \\
\quad(n=10)\end{array}$ \\
\hline Number of eosinophils ${ }^{B}$ & $2(1-2)$ & $22(14-53)^{\mathrm{F}}$ & $1(0-3)^{G}$ & $2(0-4)^{G}$ & $1(0-24)^{G}$ & $22(1-59)^{\mathrm{F}}$ \\
\hline Dense collagen deposit (\%) ${ }^{C}$ & $51(38-58)$ & $80(70-100)^{F}$ & $50(40-58)^{G}$ & $45(40-55)^{G}$ & $51(43-61)^{G}$ & $87(70-93)^{F}$ \\
\hline $\begin{array}{l}\text { Macroscopic lesions } \\
\text { (Number of mice) }\end{array}$ & $0 / 15$ & $8 / 13^{F}$ & $0 / 8^{G}$ & $1 / 18^{\mathrm{G}}$ & $0 / 10^{G}$ & $8 / 10^{\mathrm{F}}$ \\
\hline Intimal area $(\%)^{E^{\prime}}$ & $40 \pm 18$ & $79 \pm 12^{\mathrm{F}}$ & $41 \pm 17 \mathrm{c}$ & $78 \pm 19^{\mathrm{F}, \mathrm{H}}$ & $77 \pm 11^{\mathrm{F}, \mathrm{H}}$ & $65 \pm 28^{F, H}$ \\
\hline
\end{tabular}

ASyngeneic C57BL/ 6 and allogeneic (bm12) grafts were examined 40 days after transplantation. ${ }^{B}$ Eosinophil number per high-power field $\left(0.025 \mathrm{~mm}^{2}\right)$ given as medians, with minimum and maximum values in brackets. 'Percentage of the height of the dermis occupied by dense collagen deposits. Data are shown as medians, with minimum and maximum values in brackets. DDefined as loss of hair and skin hardening. EPercentage of the surface lying within the lamina elastica interna that was occupied by the intima (mean $\pm \mathrm{SD}$ ). ${ }^{F} P<0.01$ compared with syngeneic skin grafts. ${ }^{G} P<0.01$ compared with allogeneic grafts in mice injected with control mAb. ${ }^{\mathrm{H} P}<0.01$ compared with allogeneic grafts in mice injected with the anti-IL-4 mAb.

Effect of IL-5 neutralization on chronic allograft lesions. We next examined the role of IL-5 and eosinophils on chronic allograft pathology. Administration of anti-IL5 mAb TRFK-5 abrogated eosinophil infiltration within the transplant (Figure $2 \mathrm{f}$ and Table 3 ) and prevented the increase in dermal collagen (Figure $3 \mathrm{~d}$ and Table 3 ). The macroscopic counterpart of the absence of dermal fibrosis was an entirely normal aspect of the bm 12 skin allografts. However, the anti-IL-5 mAb treatment did not prevent intimal thickening of donor skin vessels that was as severe as that in mice treated with the control $\mathrm{mAb}$ (Figure $4 \mathrm{~d}$ and Table 3 ). Because this dissociation between interstitial fibrosis and vasculopathy was unexpected, we performed bm12 skin grafts on IL-5 knockout mice in order to rule out any possible bias due to the repeated injections of the rat anti-IL-5 mAb. Again, bm12 skins grafted on IL-5 knockout mice developed an obliterative graft vasculopathy (Figure 4e) but did not develop fibrosis or eosinophilic infiltrates (Table 3). Increased amounts of the fibrogenic cytokine
TGF- $\beta 1$ mRNA were detected within chronically rejected grafts compared with the basal amounts found in syngeneic skin grafts (Figure 5). The increase in TGF- $\beta$ 1 mRNA was prevented by anti-IL- 5 administration (Figure 5). Immunostaining for TGF- $\beta 1$ revealed that this cytokine was produced by several cell types, including keratinocytes and fibroblasts (not shown). Strong staining for TGF- $\beta 1$ was also observed within eosinophils, indicating that they contribute to TGF- $\beta$ production during chronic rejection of bm 12 skin allografts (Figure 6).

Effect of IL-10 neutralization on chronic allograft lesions. Finally, we investigated the effect of IL-10 neutralization on the histopathology of graft rejection. Mice that received the anti-IL-10 mAb developed fibrosis, vasculopathy, and graft eosinophil infiltrates equivalent to those observed in control animals (Table 3 ). Data given in Table 3 summarize the pathologic findings 40 days after transplantation in the different groups of mice.
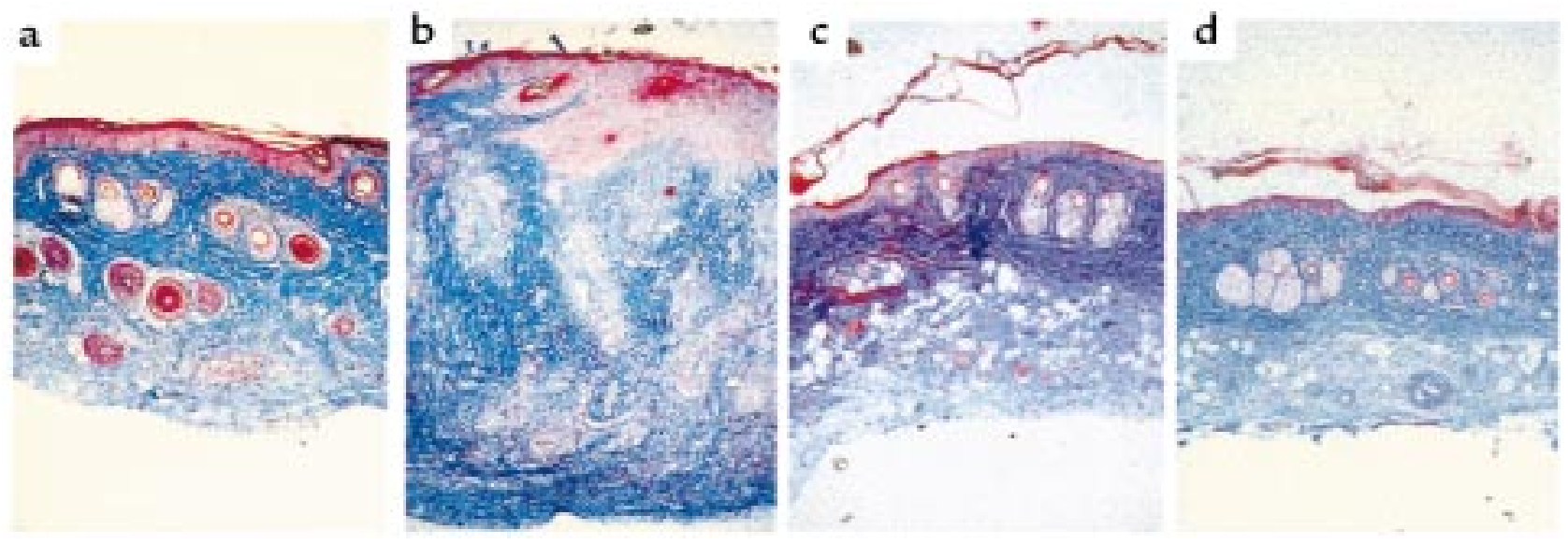

\section{Figure 3}

Allograft interstitial fibrosis: effect of IL-4 and IL-5 blockade. (a) A syngeneic skin graft 40 days after transplantation. The collagen-dense deposits normally present within syngeneic tail skin grafts are stained blue. (b) bm12 skin allograft at day 40 from a mouse that received anti-CD3 and the control mAb. The thickness of the dermis is increased, mainly because of dense collagen deposits. (c and d) bm 12 skin allografts at day 40 in mice that received the anti-CD3 mAb and either anti-IL-4 mAb (c) or anti-IL-5 mAb (d). In both settings (c and d), the collagen-dense deposits and the thickness of the dermis are comparable to that observed in syngeneic skin grafts. 

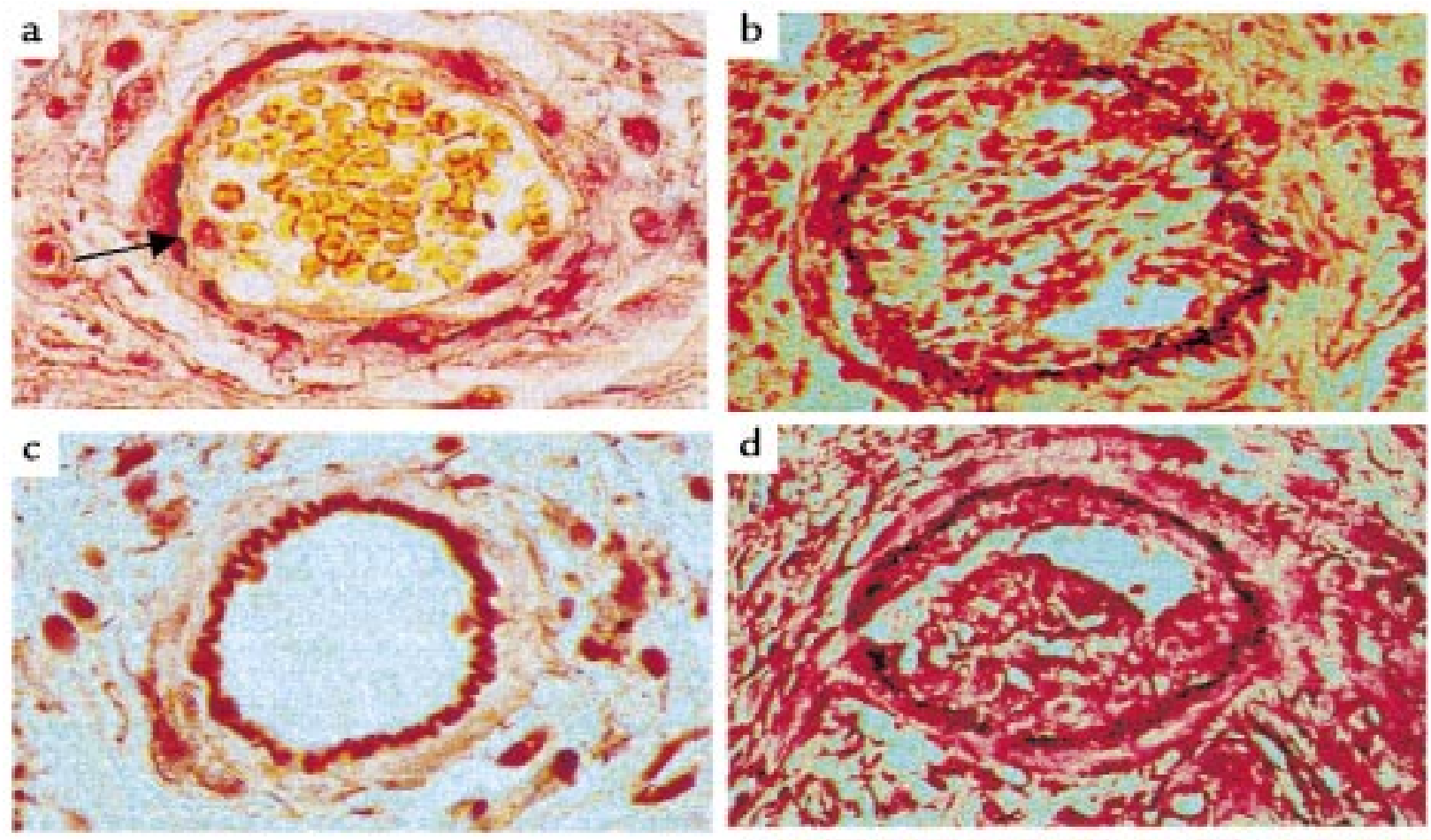

\section{Figure 4}

Allograft vasculopathy: effect of anti-IL-4 and anti-IL-5 mAb administration. (a) Normal appearance of a small artery in a syngeneic skin graft 60 days after transplantation. The lamina elastica interna, stained brown (arrow), separates the media from the intima (orcein stain, $\times 1,000$ ). (b) bm12 skin allograft at day 40 from a mouse that received anti-CD3 and the control mAb. An increased cellularity of the intima, leading to a reduction of the vessel lumen, is observed (orcein staining, $\times 400$ ). (c) bm12 skin allograft at day 40 from a mouse that received anti-CD3 and the anti-IL-4 mAb. The vessel is normal, with no intimal proliferation (orcein staining, $\times 400$ ). (d and e) bm 12 skin allograft at day 40 from a wild-type mouse that received anti-CD3 and the anti-IL-5 mAb (d), or an IL-5-deficient mouse that received anti-CD3 $\mathrm{mAb}(\mathbf{e})$. An obliterative vasculopathy is observed in both settings.

\section{Discussion}

The first significant finding from this study was that the obliterative graft vasculopathy associated with chronic rejection of MHC class II disparate murine skin allografts was dependent on IL-4 secretion. Indeed, neutralization of IL-4, which was abundantly detected at the mRNA level within chronically rejected allografts, completely prevented allograft arteriolopathy. With regard to its pathogenic role, IL-4 may stimulate the proliferation of vascular smooth muscle cells, thereby directly contributing to arterial luminal occlusion (38). In addition, IL-4 is able to induce the expression of adhesion molecules, such as VCAM-1, on numerous cell types, including endothelial cells $(34-37,39)$. This process is probably critical for triggering the alloreactive response culminating in chronic rejection, as suggested by the prevention of graft arteriolopathy by treatment with anti-adhesion molecule antibodies (40). IL-4 may also play a role in the priming of T cells for IFN- $\gamma$ production, as recently shown in vivo after challenge with tumor antigens (41). Indeed, experiments with neutralizing anti-IFN- $\gamma$ mAb and IFN-

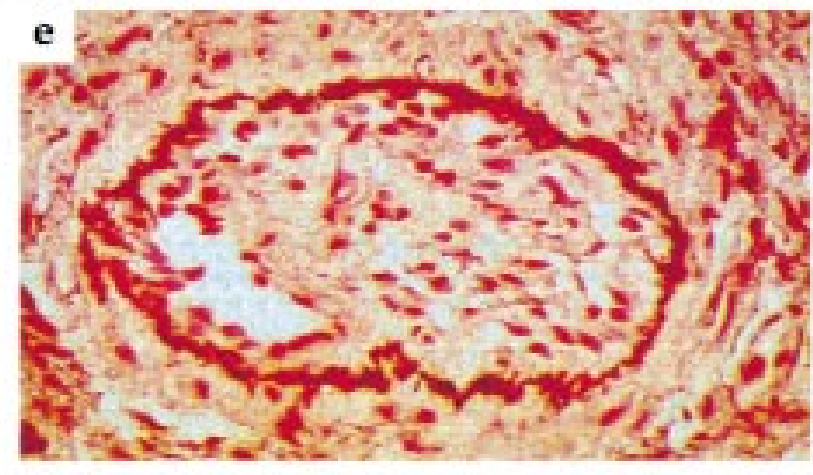

$\gamma$-deficient mice revealed that this cytokine was necessary for the development of obliterative vasculopathy in models of cardiac and aortic allografts $(3,4,42)$. While IL-4 played an obligatory role in the present model, a recent study showed that coronary graft vasculopathy did develop in IL-4-deficient mice (43). This difference might be explained by the fact that in the latter experiments, donor and recipient were disparate for MHC class I, class II, and minor alloantigens, compared with only a single MHC class II disparity in the strain combination we studied.

The second chief finding was that graft interstitial fibrosis was associated with an IL-5-dependent eosinophil infiltrate. This phenomenon is consistent with the ability of activated eosinophils to induce fibrotic lesions in several chronic inflammatory diseases $(8,9,11,13,44)$, probably by releasing a large number of cytotoxic mediators such as eosinophil cationic proteins and activated oxygen radicals $(8,11,45-47)$. Tissue eosinophilia depends invariably on the production of IL-5 by CD $4 \mathrm{~T}$ cells. Indeed, experiments using either IL5-deficient mice or neutralizing anti-IL-5 mAb revealed 


\section{Figure 5}

Effect of IL-5 neutralization on the production of TGF- $\beta 1$ mRNA in chronically rejected skin allografts. Quantitative competitive RT-PCR assay for TGF- $\beta 1$ mRNA was performed 40 days after transplantation in syngeneic skin grafts (cross-hatched bar), in mice that received anti-CD3 and control $\mathrm{mAb}$ (filled bar), and in mice that received anti-CD3 and anti-IL-5 mAb (hatched bar). Results are expressed as femtograms of TGF- $\beta$ mRNA per microgram of cellular RNA. Each experimental group represents a pool of 3 skin grafts. Similar results were obtained in another separate experiment.

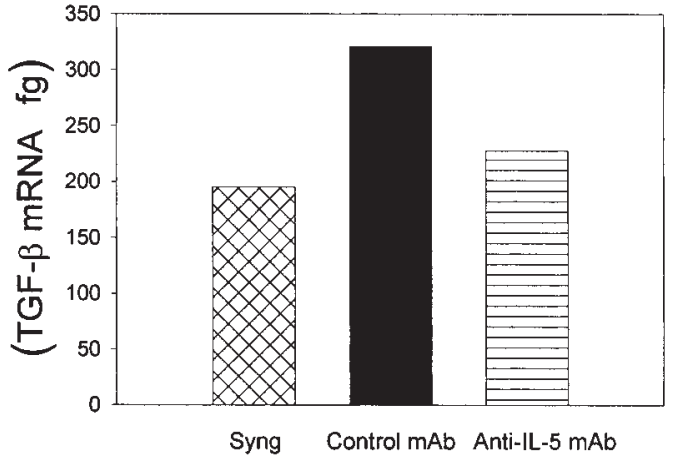

the crucial role of IL-5 in the proliferation and differentiation of eosinophils (16-18, 23, 48), as well as in their recruitment and activation within tissues (49). The observation that eosinophils and IL-5 may be present during rejection of tissue allografts has been made by several investigators in both experimental animals and humans $(47,50-55)$. Whether their presence is merely secondary, or whether eosinophils play a causative role in the rejection process, has not yet been elucidated. We investigated the role of IL-5 on the development of the eosinophil infiltrate and chronic allograft lesions by the administration of a neutralizing anti-IL-5 mAb in wildtype recipients, and by studying bm 12 skins grafted on IL-5-deficient mice. The lack of IL-5 completely prevented eosinophilic infiltration into skin allografts (16, $48,56,57)$. Importantly, this was accompanied by a complete prevention of interstitial allograft dermal fibrosis. Tissue eosinophils have been identified as a major source of TGF- $\beta$, a cytokine involved in tissue remodeling and fibrosis $(1,9,58,59)$. The presence of increased amounts of TGF- $\beta$ mRNA within chronically rejected allografts, together with a reduction of TGF- $\beta$ transcripts in mice treated with anti-IL-5 $\mathrm{mAb}$, is consistent with a role for eosinophil-derived TGF- $\beta$ in allograft fibrosis. The macroscopic counterpart of the absence of interstitial fibrosis in anti-IL-5 mAb-treated and IL-5-deficient mice was a normal appearance of the allogeneic skins, which were indistinguishable from syngeneic transplants. This finding contrasts with the graft vasculopathy, which was still present in both anti-IL-5
mAb-treated mice and IL-5-deficient mice.

Blocking experiments revealed that in addition to its role in the development of vasculopathy, IL-4 also played a crucial role in the generation of eosinophil infiltration and associated interstitial fibrosis. This is in keeping with several experimental models showing that IL-4-deficient mice are unable to mount an eosinophil infiltration within tissues. IL-4 may contribute to tissue eosinophilia by multiple mechanisms. First, this cytokine is involved in the expansion of Th2-type cells and in their ability to secrete IL-5 $(32,33,60)$. Second, as already mentioned, IL-4 triggers the expression of VCAM- 1 on endothelial cells. This adhesion molecule is also critical for the influx of eosinophils within inflamed tissues (34-37). Finally, IL-4 induces the skin to produce eotaxin $(61,62)$, a chemokine that in cooperation with IL-5 regulates the homing and activation of eosinophils within tissues $(49,62-65)$.

In summary, IL-4 plays a pivotal role in the development of fibrosis and vasculopathy during chronic rejection of $\mathrm{MHC}$ class II disparate skin grafts. We have shown that the fibrogenic effect of IL-4 is related to the infiltration of the allograft by eosinophils, because this process was secondary to an IL-5-dependent eosinophil infiltrate. On the contrary, the role of IL-4 on graft vasculopathy is eosinophil independent, shown by the fact that both IL-5-deficient and anti-IL-5 mAb-treated mice developed graft vasculopathy. Both cytokines might therefore be considered as potential therapeutic targets in the course of chronic allograft rejection.
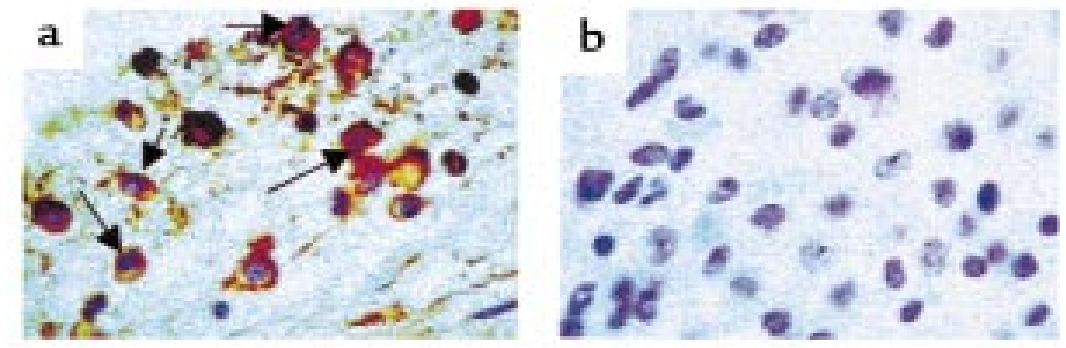

\section{Figure 6}

Immunostaining for TGF- $\beta 1$ expression in chronically rejected skin allografts. (a) TGF- $\beta 1$ staining (brown) is present within eosinophils (arrows) and other inflammatory cells $(\times 1,000)$. (b) Immunostaining of the same sample after preincubation of the anti-TGF- $\beta$ antibody with the TGF- $\beta$-specific blocking peptide as a control procedure. Only faint background staining can still be seen $(\times 1,000)$. Similar staining patterns were observed in 5 other skin allografts. 


\section{Acknowledgments}

This study was supported by a grant from the Fonds de la Recherche Scientifique Médicale, a Research Concerted Action of the Communauté Française de Belgique, a Pôle d'Attraction Interuniversitaire (Belgium), and by the Biotech programme of the European Union. A. Le Moine received an Allocation de Recherche from the Société de Néphrologie, and a scholarship from Roche given by the Société de Transplantation. Véronique Flamand is a Qualified Scientist of the Fonds National de la Recherche Scientifique (Belgium). We wish to thank M. Kopf for providing the IL-5 knockout mice, and Claude Habran and Maryline Vanderhaegen for their technical assistance.

1. Orosz, C.G., and Pelletier, R.P. 1997. Chronic remodeling pathology in grafts. Curr. Opin. Immunol. 9:676-680.

2. Shi, C., 1996. Immunologic basis of transplant-associated arteriosclerosis. Proc. Natl. Acad. Sci. USA. 93:4051-4056.

3. Nagano, H., et al. 1997. Interferon-gamma deficiency prevents coronary arteriosclerosis but not myocardial rejection in transplanted mouse hearts. J. Clin. Invest. 100:550-557.

4. Russell, P.S., Chase, C.M., Winn, H.J., and Colvin, R.B. 1994. Coronary atherosclerosis in transplanted mouse hearts. III. Effects of recipient treatment with a monoclonal antibody to interferongamma. Transplantation. 57:1367-1371.

5. Russell, P.S., Chase, C.M., Winn, H.J., and Colvin, R.B. 1994. Coronary atherosclerosis in transplanted mouse hearts. I. Time course and immunogenetic and immunopathological considerations. Am. J. Pathol. 144:260-274.

6. Russell, P.S., Chase, C.M., Winn, H.J., and Colvin, R.B. 1994. Coronary atherosclerosis in transplanted mouse hearts. II. Importance of humoral immunity. J. Immunol. 152:5135-5141.

7. Le Moine, A., et al. 1998. Chronic rejection of MHC class II disparate skin grafts after anti-CD3 therapy: a model of antibody-independent transplant vasculopathy. Transplantation. 66:1537-1544

8. Kroegel, C., Virchow, J.C., Jr., Luttmann, W., Walker, C., and Warner, J.A. 1994. Pulmonary immune cells in health and disease. I. The eosinophil leucocyte. Eur. Respir. J. 7:519-543.

9. Minshall, E.M., et al. 1997. Eosinophil-associated TGF-beta1 mRNA expression and airways fibrosis in bronchial asthma. Am.J. Respir. Cell Mol. Biol. 17:326-333.

10. Birkland, T.P., Cheavens, M.D., and Pincus, S.H. 1994. Human eosinophils stimulate DNA synthesis and matrix production in dermal fibroblasts. Arch. Dermatol. Res. 286:312-318.

11. Noguchi, H., Kephart, G.M., Colby, T.V., and Gleich, G.J. 1992. Tissue eosinophilia and eosinophil degranulation in syndromes associated with fibrosis. Am. J. Pathol. 140:521-528.

12. Gleich, G.J., and Kita, H. 1997. Bronchial asthma: lessons from murine models. Proc. Natl. Acad. Sci. USA. 94:1344-1349.

13. Kadin, M., Butmarc, J., Elovic, A., and Wong, D. 1993. Eosinophils are the major source of transforming growth factor-beta 1 in nodular sclerosing Hodgkin's disease. Am. J. Pathol. 142:11-16.

14. Tang, H., Sharp, G.C., Peterson, K.P., and Braley-Mullen, H. 1998. IFN-gamma-deficient mice develop severe granulomatous experimental autoimmune thyroiditis with eosinophil and infiltration in thyroids. J. Immunol. 160:5105-5112.

15. Hogan, S.P., Koskinen, A., Matthaei, K.I., Young, I.G., and Foster, P.S. 1998. Interleukin-5-producing CD4+ T cells play a pivotal role in aeroallergen-induced eosinophilia, bronchial hyperreactivity, and lung damage in mice. Am. J. Respir. Crit. Care Med. 157:210-218.

16. Nakajima, H., et al. 1992. CD4+ T-lymphocytes and interleukin-5 mediate antigen-induced eosinophil infiltration into the mouse trachea. Am. Rev. Respir. Dis. 146:374-377.

17. Sanderson, C.J. 1992. Interleukin-5, eosinophils, and disease. Blood. 79:3101-3109.

18. Foster, P.S., Hogan, S.P., Ramsay, A.J., Matthaei, K.I., and Young, I.G. 1996. Interleukin 5 deficiency abolishes eosinophilia, airways hyperreactivity, and lung damage in a mouse asthma model. J. Exp. Med. 183:195-201.

19. Hung, K., et al. 1998. The central role for CD4+ T cells in the antitumor immune response. J. Exp. Med. 188:2357-2368.

20. Cohn, L., Tepper, J.S., and Bottomly, K. 1998. IL-4-independent induction of airway hyperresponsiveness by Th2, but not Th1, cells. J. Immunol. 161:3813-3816.

21. Smith, J.A., and Bluestone, J.A. 1997. T cell inactivation and cytokine deviation promoted by anti-CD3 mAbs. Curr. Opin. Immunol. 9:648-654.

22. Reinke, P., et al. 1997. Selective in vivo deletion of alloactivated TH1 cells by OKT3 monoclonal antibody in acute rejection. Immunol. Lett. 57:151-153.
23. Kopf, M., et al. 1996. IL-5-deficient mice have a developmental defect in CD 5+ B-1 cells and lack eosinophilia but have normal antibody and cytotoxic $\mathrm{T}$ cell responses. Immunity. 4:15-24.

24. Leo, O., Foo, M., Sachs, D.H., Samelson, L.E., and Bluestone, J.A. 1987. Identification of a monoclonal antibody specific for a murine T3 polypeptide. Proc. Natl. Acad. Sci. USA. 84:1374-1378.

25. Schumacher, J.H., et al. 1988. The characterization of four monoclonal antibodies specific for mouse IL-5 and development of mouse and human IL-5 enzyme-linked immunosorbent. J. Immunol. 141:1576-1581

26. Boirivant, I.M., Fuss, I.J., Chu, A., and Strober, W. 1998. Oxazolone colitis: a murine model of T helper cell type 2 colitis treatable with antibodies to IL-4. J. Exp. Med. 188:1929-1939.

27. Ishida, H., et al. 1994. Continuous administration of anti-interleukin 10 antibodies delays onset of autoimmunity in NZB/W F1 mice. $J$. Exp. Med. 179:305-310.

28. Billingham, R., and Medawar, P.B. 1951. The technique of free skin grafting in mammals. J. Exp. Biol. 28:385-391.

29. Donckier, V., et al. 1995. Critical role of interleukin 4 in the induction of neonatal transplantation tolerance. Transplantation. 59:1571-1576.

30. Zuany-Amorim, C., et al. 1996. Modulation by IL-10 of antigeninduced IL-5 generation, and CD4+ T lymphocyte and eosinophil infiltration into the mouse peritoneal cavity. J. Immunol. 157:377-384.

31. Romani, B.L., et al. 1992. Neutralizing antibody to interleukin 4 induces systemic protection and $\mathrm{T}$ helper type 1-associated immunity in murine candidiasis. J. Exp. Med. 176:19-25.

32. Kopf, M., et al. 1993. Disruption of the murine IL-4 gene blocks Th2 cytokine responses. Nature. 362:245-248.

33. Kopf, M., et al. 1996. IL-4-deficient Balb/c mice resist infection with Leishmania major. J. Exp. Med. 184:1127-1136.

34. Lei, X.F., et al. 1998. Disruption of antigen-induced inflammatory responses in CD40 ligand knockout mice. J. Clin. Invest. 101:1342-1353

35. Viola, J.P.B., Kiani, A., Bozza, P.T., and Rao, A. 1998. Regulation of allergic inflammation and eosinophil recruitment in mice lacking the transcription factor NFAT1: role of interleukin-4 (IL-4) and IL5. Blood. 91:2223-2230.

36. Ying, S., et al. 1997. Associations between IL-13 and IL-4 (mRNA and protein), vascular cell adhesion molecule- 1 expression, and the infiltration of eosinophils, macrophages, and $\mathrm{T}$ cells in allergen-induced late-phase cutaneous reactions in atopic subjects. J. Immunol. 158:5050-5057.

37. Gonzalo, J.A., et al. 1996. Eosinophil recruitment to the lung in a murine model of allergic inflammation. The role of $\mathrm{T}$ cells, chemokines, and adhesion receptors. J. Clin. Invest. 98:2332-2345.

38. Natarajan, R., Rosdahl, J., Gonzales, N., and Bai, W. 1997. Regulation of 12-lipoxygenase by cytokines in vascular smooth muscle cells. Hypertension. 30:873-879.

39. Li, H., Cybulsky, M.I., Grimbone, M.A., and Libby, P. 1993. Inducible expression of vascular cell adhesion molecule-1 by vascular smooth muscle cells in vitro and within rabbit atheroma. Am. J. Pathol. 143:1551-1559.

40. Russell, P.S., Chase, C.M., and Colvin, R.B. 1995. Coronary atherosclerosis in transplanted mouse hearts. Transplantation. 60:724-729.

41. Schüler, T., Qin, Z., Ibe, S., Noben-Trauth, N., and Blankenstein, T. 1999. T helper cell type 1-associated and cytotoxic T lymphocytemediated tumor immunity is impaired in interleukin 4-deficient mice. J. Exp. Med. 189:803-810.

42. Räisänen-Sokolowski, A., Glysing-Jensen, T., Koglin, J., and Russell, M.E. 1998. Reduced transplant arteriosclerosis in murine cardiac allografts placed in interferon-gamma knockout recipients. Am. J. Pathol. 152:359-365.

43. Mottram, P.L., Räisänen-Sokolowski, A., Glysing-Jensen, T., SteinOakley, A.N., and Russell, M.E. 1998. Cardiac allografts from IL-4 knockout recipients: assessment of transplant arteriosclerosis and peripheral tolerance. J. Immunol. 161:602-609.

44. Gharaee-Kermani, M., et al. 1998. The role of IL-5 in bleomycininduced pulmonary fibrosis. J. Lenkoc. Biol. 64:657-666.

45. Gleich, G.J. 1990. The eosinophil and bronchial asthma: current understanding. J. Allergy Clin. Immunol. 85:422-436.

46. Noguchi, H., et al. 1991. Tissue eosinophilia and eosinophil degranulation in orbital pseudotumor. Ophthalmology. 98:928-932.

47. Foster, P.F., et al. 1991. Eosinophil cationic protein's role in human hepatic allograft rejection. Hepatology. 13:1117-1125

48. Coffman, R.L., Seymour, B.W., Hudak, S., Jackson, J., and Rennick, D. 1989. Antibody to interleukin-5 inhibits helminth-induced eosinophilia in mice. Science. 245:308-310.

49. Mould, A.W., Matthaei, K.I., Young, I.G., and Foster, P.S. 1997. Relationship between interleukin-5 and eotaxin in regulating blood and tissue eosinophilia in mice. J. Clin. Invest. 99:1064-1071. 
50. Chan, S.Y., DeBruyne, L.A., Goodman, R.E., Eichwald, E.J., and Bishop, D.K. 1995. In vivo depletion of CD8+ T cells results in Th2 cytokine production and alternate mechanisms of allograft rejection. Transplantation. 59:1155-1161.

51. Kondo, T., et al. 1991. Vascular rejection and graft eosinophilia in rat lung allografts. J. Surg. Res. 51:310-315.

52. Martinez, O.M., et al. 1993. Evidence for a nonclassical pathway of graft rejection involving interleukin 5 and eosinophils. Transplantation. 55:909-918.

53. de Groen, P.C., Kephart, G.M., Gleich, G.J., and Ludwig, J. 1994. The eosinophil as an effector cell of the immune response during hepatic allograft rejection. Hepatology. 20:654-662.

54. Nolan, C.R., Saenz, K.P., Thomas, C.A., and Murphy, K.D. 1995. Role of the eosinophil in chronic vascular rejection of renal allografts. Am. J. Kidney Dis. 26:634-642.

55. Ten, R.M., Gleich, G.J., Holley, K.E., Perkins, J.D., and Torres, V.E. 1989. Eosinophil granule major basic protein in acute renal allograft rejection. Transplantation. 47:959-963.

56. Sher, A., Coffman, R.L., Hieny, S., Scott, P., and Cheever, A.W. 1990 Interleukin 5 is required for the blood and tissue eosinophilia but not granuloma formation induced by infection with Schistosoma man soni. Proc. Natl. Acad. Sci. USA. 87:61-65.

57. Kung, T.T., et al. 1995. Involvement of IL-5 in a murine model of allergic pulmonary inflammation: prophylactic and therapeutic effect of an anti-IL-5 antibody. Am. J. Respir. Cell Mol. Biol. 13:360-365.
58. O'Kane, S., and Ferguson, M.W. 1997. Transforming growth factor beta s and wound healing. Int. J. Biochem. Cell Biol. 29:63-78.

59. Elovic, A.E., et al. 1998. IL-4-dependent regulation of TGF-alpha and TGF-beta1 expression in human eosinophils. J. Immunol. 160:6121-6127.

60. Constant, S.L., and Bottomly, K. 1997. Induction of Th1 and Th2 CD4+ T cell response: the alternative approaches. Annu. Rev. Immunol. 15:297-322.

61. Mochizuki, M., Bartels, J., Mallet, A.I., Christophers, E., and Schroder, J.M. 1998. IL-4 induces eotaxin: a possible mechanism of selective eosinophil recruitment in helminth infection and atopy. $J$. Immunol. 160:60-68.

62. Sanz, M.J., et al. 1998. Human eotaxin induces alpha 4 and beta 2 integrin-dependent eosinophil accumulation in rat skin in vivo: delayed generation of eotaxin in response to IL-4. J. Immunol. 160:3569-3576.

63. Ganzalo, J.A., et al. 1996. Mouse eotaxin expression parallels eosinophil accumulation during lung allergic inflammation but it is not restricted to a Th2-type response. Immunity. 4:1-14.

64. Teixeira, M.M., et al. 1997. Chemokine-induced eosinophil recruitment. Evidence of a role for endogenous eotaxin in an in vivo allergy model in mouse skin. J. Clin. Invest. 100:1657-1666.

65. Ponath, P.D., et al. 1996. Molecular cloning and characterization of a human eotaxin receptor expressed selectively on eosinophils. J. Exp. Med. 183:2437-2448. 